\title{
Automatically shedding loads for lighting systems in corridors and public areas in high-rise apartment buildings
}

\author{
Tuyen Nguyen Tai * \\ Lab Center, Posts and Telecommunications Institute of Technology Hanoi City, Vietnam.
}

Global Journal of Engineering and Technology Advances, 2021, 08(02), 056-061

Publication history: Received on 12 July 2021; revised on 14 August 2021; accepted on 16 August 2021

Article DOI: https://doi.org/10.30574/gjeta.2021.8.2.0116

\begin{abstract}
Currently, the lighting system for corridors and public areas in high-rise apartment buildings uses LED systems to replace Sodium lamps, halogen lamps... Although LED lights have been put into use, there are economic benefits such as lower power consumption and longer durability (life expectancy) according to the manufacturer's explanation. But in practice, the LEDs are used with pulse sources with operating voltages from 170VAC to 240VAC and continuous operation time without rest, often resulting in power loss due to overload or the life of the capacitor is reduced. Therefore, in order to improve the life span and efficiently use the energy source, the researches have studied the switching process control such as [1], [2], [3], [5].
\end{abstract}

This paper presents a new research direction Automatically shedding loads for lighting systems in corridors and public areas in high-rise apartment buildings for greater efficiency.

Keywords: Lighting system; LED systems; Lower power consumption; Longer durability

\section{Introduction}

In the process of use, the power supply only provides a fixed and continuous voltage, leading to continuous lighting at maximum power, causing the LED elements in the lamp to age quickly, affecting the intensity of the lamp brightness during use, LED power supplies are designed with a fairly wide voltage range, but use in areas with unstable voltages has not really brought high efficiency. For example: At the beginning of the evening from $5 \mathrm{pm}$ to $8 \mathrm{pm}$ due to the low voltage in areas with poor power quality, the power supply does not meet the maximum power for LED, the lights will be darker compared with the time from 11 am to 3 am when there are few people using electricity or few people walking in public areas and corridors. The automatic load shedding system for LED public lighting will solve the energy compensation in the early evening hours thanks to the design of the pressure compensation and load shedding mechanism, reducing the power consumption. at a time of little use. The system is used Microcontroller Atmega [2], [4], [6], [7] in controlling and monitoring the power supply process for LED lighting.

\section{Working principle of the system}

Technical solution for automatic load shedding for public lighting LEDs using real-time combined with light sensors to automatically power on, automatically shed loads, automatically Real-time power-off action brings more efficiency on light source, saving useless power consumption.

\footnotetext{
* Corresponding author: Tuyen Nguyen Tai; Email: tuyennt@ptit.edu.vn

Lab Center, Posts and Telecommunications Institute of Technology Hanoi City, Vietnam. 


\subsection{Structure, principle}

Connect the circuit block to the lighting system.

In figure 1, the load shedding automatic coupling diagram for LED public lighting uses real-time auto power on, auto load shedding, real time auto power off.

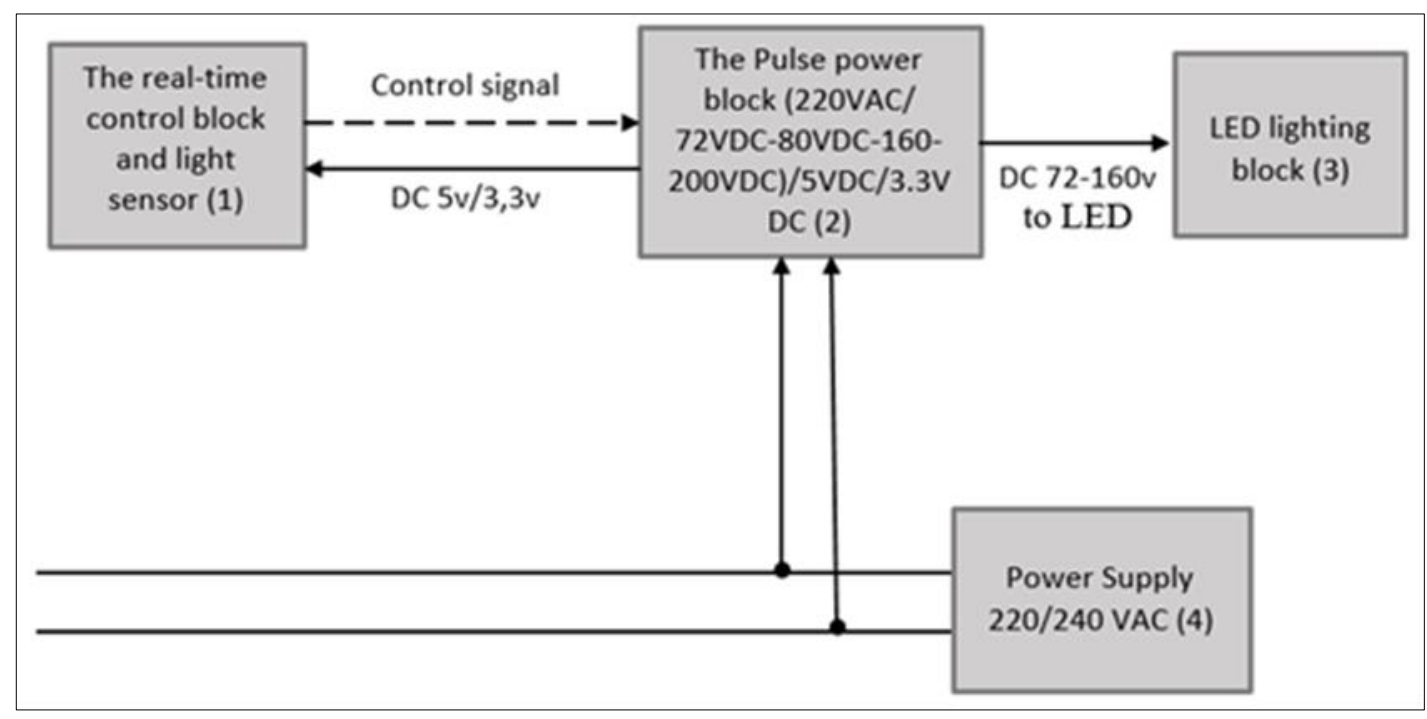

Figure 1 Load shedding automatic coupling block for real-time public lighting LEDs

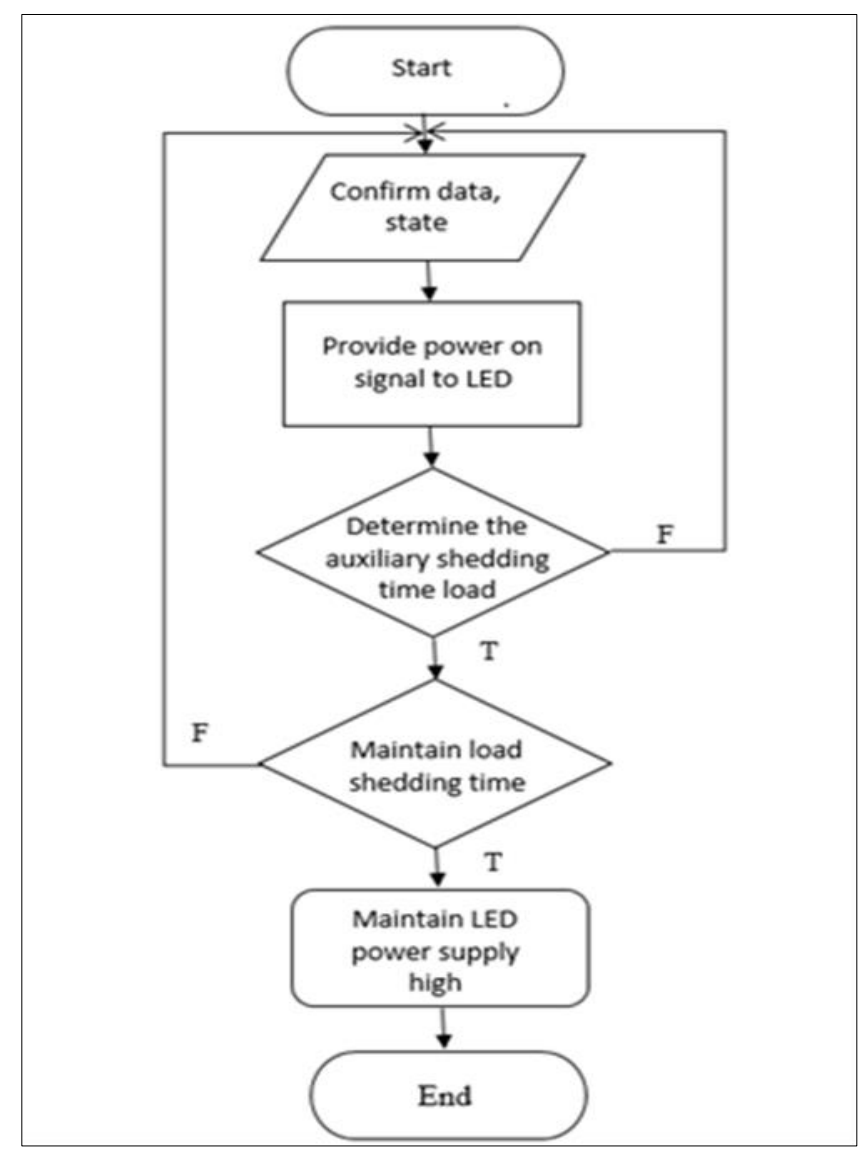

Figure 2 Block diagram of the program 
In Figure 1, the real-time control block and light sensor (1) are designed with real-time IC Realtime Clock DS1307 M021 with power supply using 3v Lithium rechargeable battery to maintain system time. (Time may vary from 3-7 minutes per year). The real-time block can be designed to allow the user to set the hour and time of load shedding and the time to turn on and off the lighting system or design to allow the default setting of the on, off, and off time. load and set operating hours with a default key. The control signal from block (1) will send a signal to block (2) Pulse source block (220VAC/72VDC-80VDC-160-200VDC)/5VDC/3.3VDC to regulate output voltage supplied to LED elements lighting (3), block 2 also has the function of supplying 3.3v and 5v DC power to block (1). Block (3) LED lighting block.

- Algorithm diagram of the program

Step 1. Initialization (starting program)

Step 2. Confirm data, state

Step 3. Provide power on signal to LED

Step 4. Determine the auxiliary shedding time load (low power supply)

+ If false go back to step 2

+ If true, go to step 5

Step 5. Maintain load shedding time (counting load shedding time)

+ If false go back to step 2

+ If correct go to step 6

Step 6. Maintain LED power supply high

Step 7. Finish

- Circuit diagram

a. Power supply circuit using IC LM1117

b. Circuit diagram of LED power supply with load shedding control

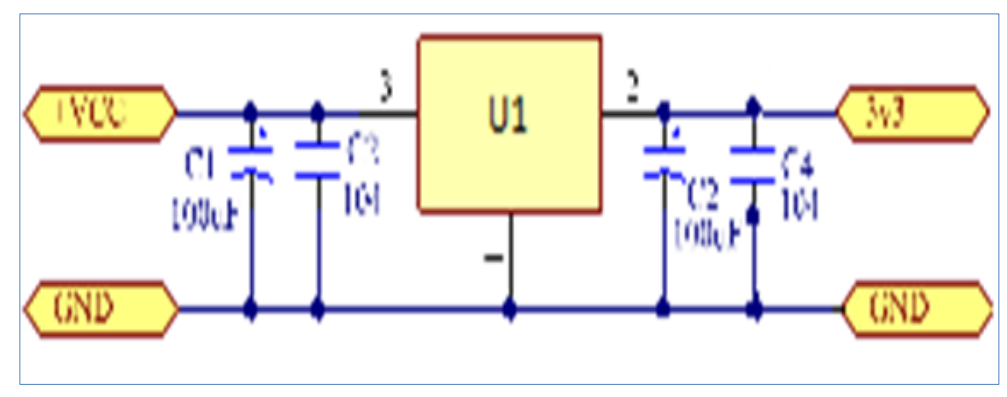

Figure 3 3v3 power supply circuit

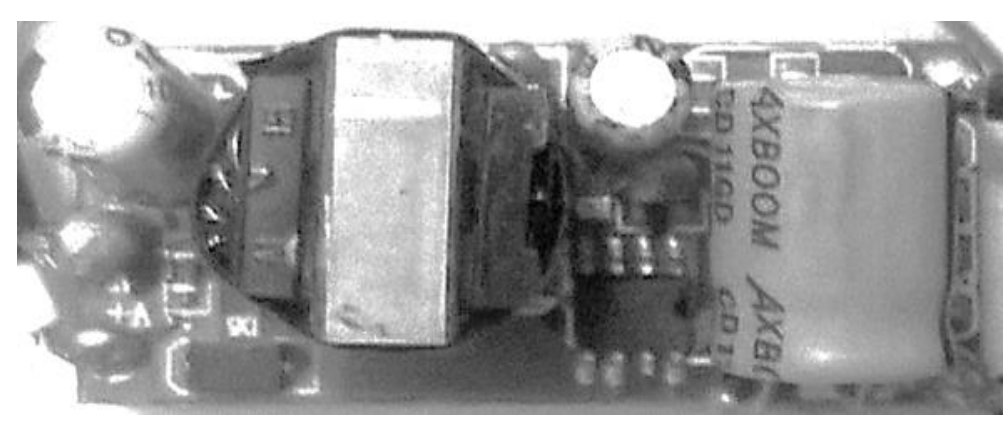

Figure 4 Circuit VAC220v/VDC160-VDC82-VDC72

In Figure 4, the 220VAC voltage source is converted to DC voltage by the rectifier bridge and input filter capacitor, then DC voltage is applied to the voltage converter IC from DC to pulse form coupled with pulse transformer to get $72 \mathrm{v}-80 \mathrm{v}$ $160 \mathrm{v}$ voltage and diode combined filter capacitor to produce lower DC voltage. In order to derive voltages at different levels, the circuit uses resistor values coupled by controlled electronic switching. These switches are controlled by signals generated from the real-time circuit programmed on the computer or manually set on the circuit. 


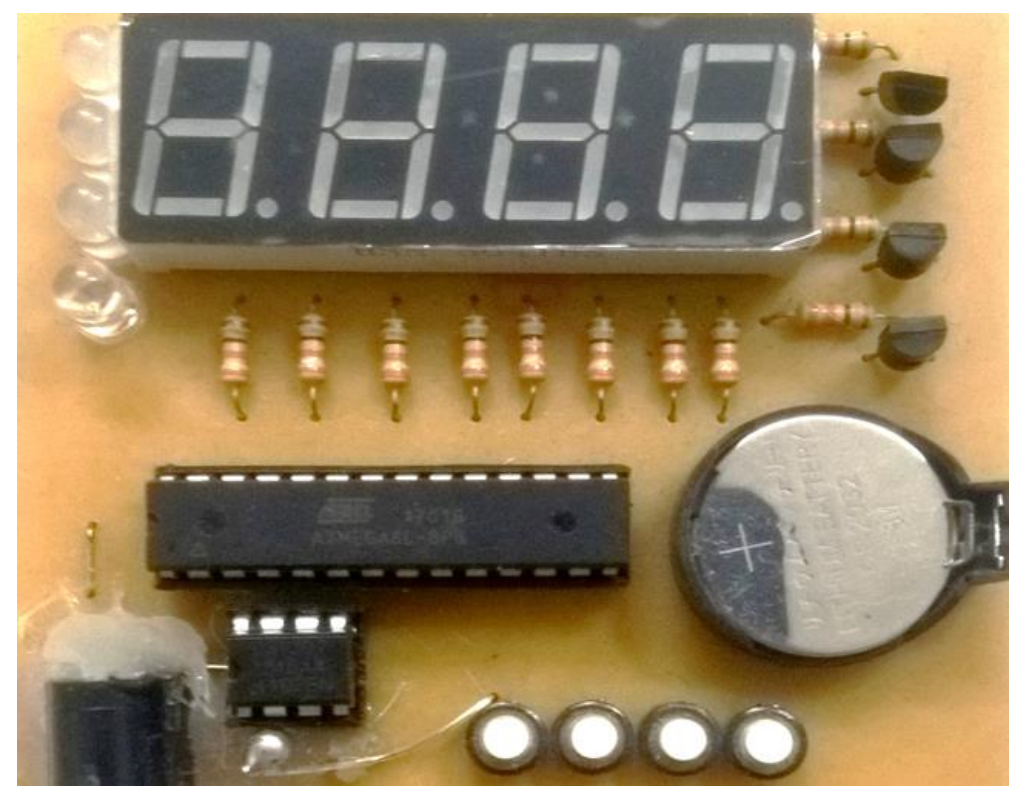

Figure 5 Load shedding control real-time circuit allows to set the load shedding mode according to the actual needs of the intended use

In Figure 5, the experimental circuit programmed by the author allows the user to Use custom and set automatic load shedding time, actual load shedding needs of each locality. The circuit includes programmable IC, real-time IC, redundant power supply, 5VDC power input, LED display of real-time and setting information, load shedding time

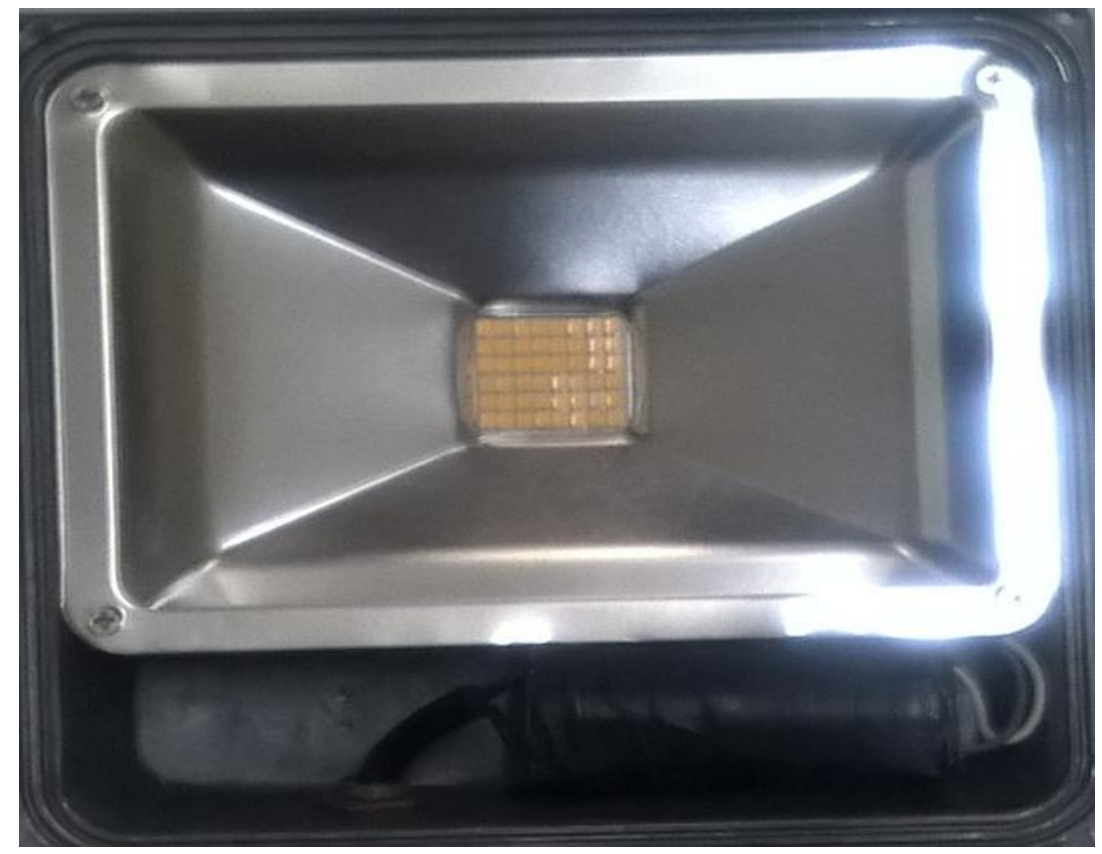

Figure 6 LED lights with automatic load

Shedding circuit In Figure 6, a 20W LED lamp is fitted with an automatic load shedding circuit. In fact, LEDs with a capacity of $20 \mathrm{~W}, 50 \mathrm{~W}, 100 \mathrm{~W}$ and $200 \mathrm{~W}$ are used with the included source circuit with only one power level (single luminous intensity). Therefore, the power consumption depends on the input power and the lighting power is only fixed at a fixed level from when the power is powered up until the power is turned off. 


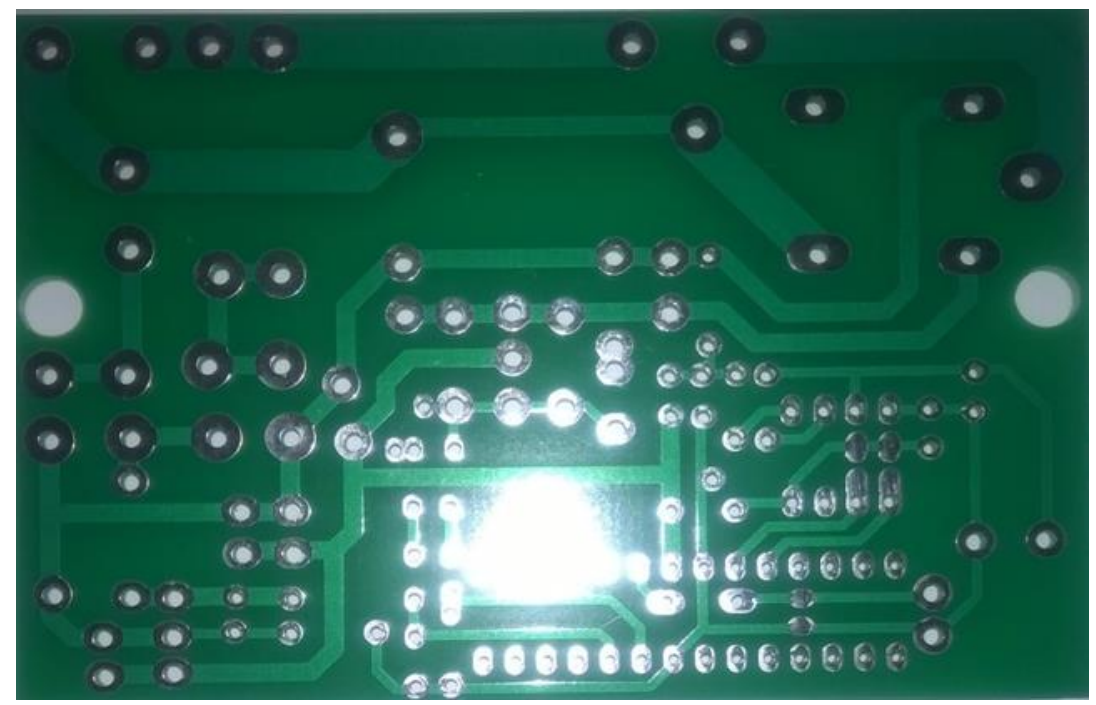

Figure 7 The printed circuit board is designed to integrate the voltage converter block, light sensor, real time and automatic load shedding power block

In Figure 7, the circuit board is designed to integrate functional blocks., shown in Figure 1. The circuit uses a common source with the pulse source circuit of the LED but different output voltage.

\section{Experimental results}

- The test system is evaluated Value of benefits obtained:

+ Automating public lighting system with automatic load shedding utility, reducing useless power consumption, increasing the life of LED lighting eyes.

+ Users are not afraid to forget to turn on and off the lighting power according to different time frames, but in practice the execution is not effective.

+ Improve the lifespan of LEDs;

+ The product was tested at a private house 49 lane 191 Trung Van street, Nam Tu Liem district, Hanoi.

+ Apply to the road lighting system between villages, communes and townships in Thanh Hoa.

\section{Conclusion}

The automatic load shedding system for LED public lighting will bring benefits such as saving electricity, increasing and reducing the light source during the required hours. The switching time is pre-programmed or user-configured for user convenience.

Necessary conditions to apply the initiative:

+ The solution is suitable and applicable to the existing public lighting system but the efficiency is not high.

+ The system operates in a normal temperature environment, the device is isolated from the water source and is radiated by the LED light housing.

+ Used for public light extraction systems, street lights at different levels in apartments, schools, offices, public houses, roads, etc. 


\section{Compliance with ethical standards}

\section{Acknowledgments}

The author gratefully acknowledge the Posts and Telecommunications Institute of Technology, Vietnam for supporting this work.

\section{Disclosure of conflict of interest}

The author declare that they have no conflicts of interest.

\section{References}

[1] Dedi Setiawan, Ishak, Muhammad Ardiansyah Sembiring, Control System for Adjusting the Brightness Level with PWM. Technique Using Visual Net Microcontroller-Based, Journal of Robotics and Control. 2020; 1(4).

[2] Karan Sharma, Kunal Mandil, Nancy Gupta. Power Saver Street Lighting Using Microcontroller Using Atmega. Communication, Integrated Networks \& Signal Processing-Cinsp 2018, vol.5 (iss.2: se): february. 2018; $107-113$.

[3] Leo Louis. Working Principle of Arduino and Using it as a Tool for Study and Research, International Journal of Control, Automation, Communication and Systems (IJCACS). April 2016; 1(2): 21-29.

[4] Lê Minh Đức, Nguyễn Thành Trung. Thiết kế bộ điều khiển tự động hệ thống chuông báo giờ học tại Trường Đại học Lâm nghiệp, Tạp chí Khoa học và Công nghệ Lâm nghiệp số 4, Trang. 2018; 315-143.

[5] Nguyễn Thành Bắc, Vũ Ngọc Quỳnh. Research Simulate Automatic Control Circuits of Headlights for Vehicle Using Light Dependent Resistor Sensors, Tạp chí Khoa Học và Công Nghệ, Trang. 2020; 84-88: 56 - Số 3, 6.

[6] Vũ Thị Oanh, Phạm Thị Hồng Anh, Vũ Thạch Dương, Hoàng Thị Thương. Điều Khiển Nhiệt Độ Lò Lên Men và Ủ Bánh Mỳ, Tạp chí Khoa Học \& Công Nghệ. 2017; 166 (06): 37 - 40, 5.

[7] Tuyen Nguyen Tai. Smart Sensors in Automatic Power On Off for Projector Based on User Monitoring Signals, International Journal of Research in Engineering and Science (IJRES). October. 2016; 4(10): 51-55. 